\title{
Representações de território: entre o discurso oficial e o discurso Kinikinau
}

\section{Territory representations: between the official discourse and the Kinikinau discourse}

Daniele Lucena Santos*

Universidade Federal de Mato Grosso do Sul

Anastácio - Mato Grosso do Sul / Brasil

\begin{abstract}
RESUMO: Inscrito no campo teórico da Análise de Discurso de vertente francesa dialogando com a corrente epistemológica dos estudos culturalistas, este trabalho objetiva problematizar o processo identitário dos Kinikinau e analisar as representações de território presentes no discurso do documento oficial das Diretrizes Curriculares Nacionais para a Educação Escolar Indígena na Educação Básica (2012) e no discurso dos próprios Kinikinau, da região de Porto Murtinho (MS).
\end{abstract}

PALAVRAS-CHAVE: identidade; representação; território; kinikinau.

ABSTRACT: This work, inscribed in the theoretical field of French Discourse Analysis and dialoguing with the epistemological current of Culturalist Studies, aims to problematize the identity process of the Kinikinau and to analyze the territory representations present in the discourse of the official document of the National Curricular Guidelines for Indigenous School Education in Basic Education (2012) and in the own Kinikinau discourse from the region of Porto Murtinho (MS), Brazil.

KEYWORDS: identity; representation; territory; Kinikinau.

\section{Introdução}

Nas últimas décadas as questões indígenas têm alcançado status na sociedade, em especial pela atuação de entidades não governamentais (ONGs), de estudiosos que se interessam pelo assunto e das universidades que, engajadas na causa indígena, subsidiam o desenvolvimento de trabalhos gerando um deslocamento histórico e social da questão. Instigadas pelas dissonâncias que o tema provoca e reconhecendo o campo profícuo sobre as questões indígenas, temos como objetivos problematizar a construção

$\overline{\text { *lucena.ufms@hotmail.com }}$ 
identitária dos Kinikinau e analisar as representações de território/terra ${ }^{1}$ que emergem do discurso oficial das Diretrizes Curriculares Nacionais para a Educação Escolar Indígena na Educação Básica (2012) e do discurso Kinikinau.

Compreendemos que discutir ambas as discursividades, produzidas em domínios discursivos diferentes, permite-nos elaborar conhecimentos mais pertinentes às nossas realidades sócio-históricas e culturais, e desconstruir determinados estereótipos arraigados na sociedade hegemônica. O corpus é constituído pelo discurso oficial e pelo discurso Kinikinau, este, por sua vez, coletado por meio de entrevistas com quatro membros da comunidade, a partir de um questionário semiestruturado. Para este texto, selecionamos apenas um recorte, designado de R2, de um dos sujeitos (SP1), sendo R1 o recorte retirado do documento oficial, com base no método arqueogenealógico de Foucault (2007), rastreando as regularidades do discurso e as relações de força.

Entendemos que analisar o discurso Kinikinau constitui-se como um gesto de resistência, especialmente nossa na condição de pesquisadoras, uma vez que, ao desenvolvermos uma pesquisa baseada em discursos ainda pouco explorados, rompemos com a tendência acadêmica a só legitimar autores e objetos de análise consagrados e de grande circulação ou repercussão. E, motivadas pelo "movimento sulear" (KLEIMAN, 2013, p. 41), trazemos à reflexão discursos que promovem a desconstrução de conhecimentos cristalizados como "verdadeiros", gerados em espaços hegemônicos.

Desse modo, o desenvolvimento de pesquisas voltadas à problematização de discursos marginalizados permite-nos elaborar e (re)significar conhecimentos que atendam às necessidades de um "lugar subalterno por excelência”, conforme Nolasco (2013, p. 12). Pautando nessas questões, mobilizamos os fios pelos quais se entrelaçam Análise do Discurso (AD) e Estudos Culturalistas, numa perspectiva transdisciplinar, visando acionar os principais conceitos que subsidiam nossas interpretações.

\section{O povo Koinukunoen ${ }^{2}$}

Remanescentes da nação Chané-Guaná, os Kinikinau são nativos da região do Chaco Paraguaio, mas "migraram para o Brasil em,

\footnotetext{
${ }^{1}$ Entendemos terra e território como sinônimos.

${ }^{2} \mathrm{Na}$ língua indígena, Koinukunoen significa Kinikinau.
} 
aproximadamente, 1850", explica Souza (2008, p. 38). A travessia para as terras brasileiras, motivada em especial por disputas territoriais, foi impulsionada pela busca de (re)construir a história e um (novo) lugar Kinikinau. As perseguições por terra, no entanto, não cessaram e os conflitos entre fazendeiros e índios foram intensificados pela Guerra da Tríplice Aliança.

Mais conhecida como Guerra do Paraguai, o combate gerou a dispersão desse povo dos territórios de Agaxi e Albuquerque, localizados entre Miranda e Aquidauana, e Corumbá e Miranda, respectivamente, sendo este último ratificado pela comunidade como território tradicional. Em razão da crescente "apropriação" das terras por parte dos fazendeiros e posseiros da região, os Kinikinau, objetivando a sobrevivência, assumiram a identidade Terena. Esse gesto provocou um discursivo desaparecimento, uma vez que o povo foi considerado extinto nas décadas de 1960 e 1970 por renomados pesquisadores. Em consonância com o "desaparecimento”, os Kinikinau enfrentaram a invisibilidade por parte dos órgãos competentes: primeiro pelo Serviço de Proteção ao Índio (SPI) e depois pela Fundação Nacional do Índio (Funai), visto que "as crianças que nasciam na aldeia eram registradas como Terena”. (SOUZA, 2012, p. 19).

Envolvidos pelas mencionadas circunstâncias, esses indígenas foram orientados pelo extinto SPI, em 1940, a seguirem para a Aldeia São João, Reserva Indígena Kadiwéu, próxima do município de Bonito/MS, onde encontrariam terras para construir suas casas e cultivar suas plantações. Desde 1940, eles coabitam a reserva com os Terenas e os Kadiwéu, donos da terra. Há informações, entretanto, de que "quatro famílias migraram dessa aldeia em virtude dos atritos com os Kadiwéu e atualmente moram na Terra Indígena de Cachoeirinha, no Assentamento Mãe Terra, em Miranda, junto com os Terenas". (SANTOS, 2014, p. 7).

Mediante esse cenário, autodeclarar-se Kinikinau foi uma decisão estimulada pela proposta de instalação de uma escola na Aldeia São João, que atendendo a demanda da comunidade, onde a maioria é Kinikinau, recebeu o nome de Escola Municipal Indígena Koinukunoen, o que permitiu o fortalecimento do povo na comunidade e o trilhar de novos caminhos. Ainda que a tensão tenha aumentado pela construção da instituição, os Kinikinau valem-se desse ambiente para reivindicar seu lugar de cidadãos brasileiros, em especial seu lugar de índios brasileiros, muitas vezes silenciado pelo Estado. 
Em face da relação tecida pelos Kinikinau com a escola e o território espacial, em Agaxi e Albuquerque, e simbólico, na aldeia São João, compreendemos que relacionados de maneira peculiar a escola e o território são dois conceitos que atravessam o processo identitário desse povo, nesse viés, partimos do pressuposto de que ambos vão além das concepções limítrofes de espaço educacional e extensão geográfica, assumindo, pelas práticas do grupo, novas representações. Em razão, porém, de nossos objetivos, delimitamos nosso olhar apenas as representações de território.

\section{Aspectos teóricos e metodológicos da pesquisa}

\subsection{Conceitos da Análise do Discurso}

A Análise do Discurso (AD) não busca o sentido verdadeiro, debruçase, no entanto, sobre o "real sentido articulado na materialidade linguística e histórica" (ORLANDI, 2009, p. 59). Dessa forma, o crucial é compreender o que está além do dito, além da materialidade linguística, ou seja, é necessário cercar o enunciado em toda a sua "estreiteza e singularidade", a fim de determinar por meio da escolha do enunciado as condições dessa alternativa. (FOUCAULT, 2008, p. 31).

Refletir sobre o discurso é considerar que sua produção se dá em uma conjuntura sócio-histórica e ideológica específica e que sua aparição é sempre recorrente de conflito, instigada por poder e resistência e emergente na descontinuidade histórica. Segundo Foucault (2004, p. 23), o poder é "uma rede que atravessa todo o corpo social" e manifesta-se por meio do discurso, criando a ordem do discurso: um sujeito tem o poder (o saber e a voz) e exerce esse poder sobre outro sujeito.

Assim como sua produção, os sentidos compilados em cada um dos discursos estão intimamente relacionados ao sujeito e à posição que ocupa na sociedade, de modo que, para Foucault (2008), o sujeito é uma "fabricação social" que pode ocupar várias posições e identificar-se com cada uma delas, mudando apenas a ordem das discursividades. Essas ordens discursivas estão ligadas às perspectivas ideológicas das quais os sujeitos compartilham e que implicam um complexo jogo de determinações históricas, que especificam "o que é e o que dever ser" das palavras e dos sentidos a elas conferidos. (PÊCHEUX, 1988, p. 159).

A partir das escolhas discursivas, obedecendo às regularidades no funcionamento do discurso, é corroborada a existência de uma formação 
discursiva. Foucault (2008, p. 43) ressalta que quando se "[...] puder descrever, entre um certo número de enunciados, semelhante sistema de dispersão [...] se puder definir uma regularidade [...] diremos, por convenção, que se trata de uma formação discursiva".

Ao compreendermos que a produção dos discursos está sempre condicionada a regularidades é desvelada a presença do outro no dizer, de outras vozes. A ideia de que um discurso se constitui a partir de um dito já-lá ${ }^{3}$, de um saber que faz referência a um discurso pré-construído existente antes na memória e que se consolida no dizível, na fala, é ratificada por Pêcheux (1988). Essa interdiscursividade é constitutiva da linguagem, pois "algo fala, sempre antes, em outro lugar e independentemente", um dizer anterior que marca a possibilidade de irrupção de "novos" discursos. (PÊCHEUX, 1988, p. 160-161).

Entrelaçado aos conceitos de discurso, interdiscurso e formação discursiva, já discutidos, a noção de arquivo é indispensável, visto que o arquivo constitui-se como um princípio de enunciabilidade, isto é, o arquivo é que permite que os enunciados adquiram sentido. Para Foucault (2008, p. 143-144), arquivo é como "a lei do que pode ser dito, o sistema que rege o aparecimento dos enunciados como acontecimentos singulares. [...] São todos esses sistemas de enunciados (acontecimentos de um lado, coisas de outro) que proponho chamar de arquivo".

Nesse viés, esses elementos colaboram para a formação de uma memória discursiva, uma vez que nos discursos há um domínio da restituição, do resgate do fio de significância, ou seja, uma repetição e, em alguns casos, uma (re)significação de algo. Saber, portanto, como os discursos funcionam é, segundo Orlandi (2009, p. 10), "colocar-se na encruzilhada de um duplo jogo da memória: o da memória institucional que estabiliza, cristaliza e, ao mesmo tempo, o da memória constituída pelo esquecimento que é o que torna possível o diferente, a ruptura, o novo".

Buscamos encontrar pelas camadas sedimentares da história, as relações de poder que ensejam determinados discursos e escamoteiam outros. No entanto, como a linguagem, na perspectiva discursiva, não é transparente, mas passível de falhas e lapsos por parte do sujeito, utilizamos o método arqueogenealógico foucaultiano $(2007,2012)$ para problematizar

\footnotetext{
${ }^{3}$ Por ser um termo técnico da área, optamos por manter o uso do hífen, assim como nas palavras já-dito, entre-lugar e entre-línguas.
} 
as discursividades. Nesse contexto é asseverada nossa tarefa de que, enquanto analistas do discurso, "consiste em problematizar os enunciados concretos em sua historicidade, descrevendo e analisando os fatores que permitiram que esses enunciados se inter-relacionassem, se negassem, se excluíssem, se substituíssem”. (SOUSA, 2011, p. 112).

\subsection{O movimento de identificação}

Discutir a questão da identidade implica argumentar sobre outros conceitos como cultura, língua e contextos políticos e econômicos, uma vez que a noção de identidade sofreu significativos deslocamentos, migrando de uma tendência fixa para uma fluida e dinâmica, diante das novas perspectivas epistemológicas. Em razão das mudanças do ponto de vista promovidas pelos estudos culturalistas e/ou pós-modernos, além de outras vertentes, a concepção de identidades, no plural, está abrindo novas possibilidades para se compreender o sujeito contemporâneo, envolvido no cenário moderno e tecnológico, no qual as relações sociais, culturais, políticas e econômicas que estabelece estão em constante (trans)(de)formação.

Refletir sobre a construção identitária dos Kinikinau é um desafio, de modo que os processos e as filiações histórico-sociais que envolvem esses sujeitos são bastante complexos. A convivência do grupo com outros povos, a influência de diferentes costumes e línguas formam um interstício, um ponto de convergência no processo identitário do povo. Pensar o sujeito "entre-línguas" (CORACINI, 2007, p. 120) implica considerar como os sentidos são construídos por esse sujeito, já que a língua é um espaço onde os sentidos são contornados, e mais: é na/pela língua que reconhecemos as tessituras culturais, históricas e ideológicas.

Ao discorrer sobre a relação entre língua e cultura, Orlandi (2005, p. 233) explica que tudo significará por meio da cultura, bem como os próprios ensinamentos dentro do ambiente de uma sala de aula para um povo podem fazer sentido enquanto para outros não, assim como na maioria das vezes nós brancos ${ }^{4}$ não compreendemos determinadas ações e posicionamentos assumidos por comunidades indígenas, por exemplo, a relação com o meio ambiente.

\footnotetext{
${ }^{4}$ A expressão foi adotada a partir da perspectiva de Hall (2005) por englobar todos os sujeitos que não se autoidentificam indígena.
} 
A princípio, Coracini $(2007$, p. 210$)$ relacionava a construção da identidade com a questão da representação. Para a autora, a noção é inerente às relações estabelecidas pelo sujeito com o outro, com o que the é exterior. Em suas palavras, “[...] toda representação se constrói a partir das experiências pessoais, mas não apenas: elas se constroem a partir das experiências dos outros, daqueles que nos cercam e que nos levam a crer nisto ou naquilo, que nos dizem quem somos". (CORACINI, 2007, p. 240).

Em consonância com a autora, Hall (2013) diz que a representação é construída pelo simbólico e age na classificação das coisas e seres em relação ao mundo. Ela é o fruto de todas as relações que determinado sujeito construiu com as coisas, com o mundo e, a partir disso, produziu significados. Nesse sentido, a representação é a produção dos sentidos em face das relações que o sujeito, em determinada posição sócio-histórica e ideológica, estabelece com o mundo e seus constituintes.

Segundo Hall (2013, p. 69), o fenômeno globalizador, a partir da década de 1950, gerou uma avalanche de transformações no cenário político, econômico e social, desestabilizando concepções tidas como norteadoras aos sujeitos. As identidades que por tanto tempo foram consideradas fixas começaram a ser transpostas pelos processos de globalização, de modo que iniciaram a desconstrução de modelos seculares e o surgimento de novas identidades, identidades híbridas, "construídas e reconstruídas na diferença”. (CANCLINI, 2015, p. 126).

$\mathrm{Na}$ tessitura da identidade, a noção de cultura precisa ser mobilizada, já que ela é um dos fios pelos quais emanam os sentidos das práticas discursivas do sujeito. Para Cuche (1999, p. 45), “cada cultura é dotada de um 'estilo' particular que se exprime através da língua, das crenças, dos costumes, também da arte [...] que influi sobre o comportamento dos indivíduos". Logo, a cultura é uma produção, uma questão de "tornar-se". (HALL, 2013, 49).

Como não vivemos sob a navalha de uma única cultura, e sim o pluriculturalismo, mesmo porque "nossas sociedades se interconectaram globalmente e tornaram-se culturalmente inter-relacionadas" (CASTELLS, 2010, p. 19). Na visão de Bauman (2005, p. 18), identidade e pertencimento não são sólidos, pelo contrário "são negociáveis e revogáveis". O autor atribui à noção de identidade, considerando sua instabilidade, a complexidade de um quebra-cabeça com peças conflitantes e que nunca se completam, pois para ele "uma identidade coesa firmemente fixada e solidamente construída seria um fardo, uma repressão, uma limitação da liberdade de escolha". (BAUMAN, 2005, p. 60). 
O movimento de transitar entre diferentes territórios, culturas, línguas e saberes provoca nesses indígenas uma miscelânea de processos identificatórios, já que as fronteiras entre indígenas e brancos não estão mais rígidas como no passado, a própria modernidade as sucumbiu. Com base nisso, a identidade ou o processo de sua construção desvela aspectos que estão imbricados em razão do constante conflito, proporcionando ao sujeito diversos deslocamentos e (des)construções, visto que após esse trânsito ele nunca é o mesmo, pois incorpora, de forma conflitante, o que está a sua volta, transformando-se em face de suas ideologias e também do que lhe falta. Por estar em relação com o outro, com o diferente, com o que lhe causa estranhamento, o sujeito é perpassado pelo "processo agonístico". (BHABHA, 2007).

Atravessados pela modernidade, os sujeitos se veem em constante necessidade de atualização, de tornar-se outro para acompanhar as mudanças aceleradas no mundo, a atualização das informações em tempo real no mundo inteiro, e assim não ficar deslocados, desconectados. Em meio à era da informatividade e do encurtamento das relações, Augé (2006, p. 103) cunha o termo "sobremodernidade". Para o autor, hoje o contexto é planetário, de modo que não podemos mais pensar em sujeitos singulares, fechados em seus territórios e culturas, já que o trânsito se torna necessário para a sobrevivência, possibilitando sua visibilidade e a da outro sobre si em espaços globais.

\section{Representações de território: entre o discurso legal e o discurso Kinikinau}

As Diretrizes Curriculares Nacionais para a Educação Escolar Indígena na Educação Básica (2012) ${ }^{5}$ são atualmente referência para o ensino nas comunidades, uma vez que regem a aplicabilidade dos princípios da escolarização nas escolas indígenas e delegam aos povos maneiras de (con)viver no espaço escolar, entretanto, a(s) voz(es) que ecoa(m) no/do documento não são indígenas.

O discurso da lei, configurando-se como um dispositivo, uma rede de poderes, está vinculado a outro(s) discursos(s), promove a (des)(re)

\footnotetext{
${ }^{5}$ Ainda que o documento estabeleça as diretrizes para a educação escolar indígena, representações de território se fazem presentes.
} 
construção das identidades e o agenciamento de discursos modalizadores sobre inclusão e exclusão, tendo em vista que "todo arquivo responde a estratégias institucionais de organização e conservação de documentos e acervos, e [...] de gestão da memória de uma sociedade". (ZOPPIFONTANA, 2005, p. 97).

No documento oficial, o processo de educação escolar indígena aparece, na maioria das vezes, associado ao território, possibilitando a interpretação de que o território é um bem que antecede qualquer outro e torna-se perene na constituição dos sujeitos. Esse bem pode, todavia, configurar o sentido material ou a valoração afetiva, a depender da situação sócio-histórica e ideológica em que o sujeito está inserido. Com base nesse viés, as diretrizes determinam: "R1: Art. $7^{\circ}$ \ $4^{\circ}$ : A Educação Escolar Indígena deve contribuir para o projeto societário e para o bem viver de cada comunidade indígena, contemplando ações voltadas à manutenção e preservação de seus territórios e dos recursos neles existentes". (BRASIL, 2012, p. 37, grifo nosso).

É relevante destacar a repetição da construção de um discurso deôntico em deve contribuir, indicando a obrigatoriedade da educação escolar em alcançar seus objetivos por meio de um projeto societário e do bem viver das comunidades. Ao enunciar projeto societário o legislador referenda a produção de um movimento que integre as comunidades à sociedade nacional, sociedade branca, pois o sentido dicionarizado do termo societário é "referente à sociedade; integrante dessa sociedade". (BECHARA, 2011, p. 1056). Em seguida, é atribuída como dever a proposta de um bem viver às comunidades, forma de estabelecer um princípio de compromisso da escola e do Estado para com os índios, visto que a história nos relata os conflitos ideológicos gerados pela interpretação dos colonizadores acerca do "bem viver" dessas comunidades. Ou seja, o bem viver discursivizado pelo documento transita entre os sentidos arrolados na formação discursiva colonial, via discurso do branco, e a formação discursiva cultural, expressa no discurso do índio.

Ao afirmar a necessidade de contemplar, via processo de escolarização, “ações voltadas à manutenção e preservação de seus territórios e dos recursos neles existentes", emergem fios de sentido que nos permitem interpretar, por meio do uso do pronome seus, articulado com a função anafórica, a separação, o distanciamento entre os territórios indígenas e os territórios dos brancos. Esse limite, estabelecido pelos brancos, funciona ambiguamente. Por um lado, gera o sentido de oportunizar a posse de um 
território que já pertence a eles, aos indígenas, e com isso a preservação de suas tradições; por outro, o de que o Estado, ao determinar a demarcação de terras para essas comunidades, destina-os a uma condição de excluídos: é necessário que eles se mantenham em seus territórios.

O termo "preservação" traz o sentido de "colocar ao abrigo de estrago, dano" (BECHARA, 2011, p. 951) algum objeto, nesse caso o território e os recursos nele existentes. É sabido que preservar não provém, naturalmente, do discurso do índio, mas passou a fazer parte depois das expressivas intervenções do homem sobre a natureza.

A partir da ação dos brancos, começou a reverberar-se a necessidade de preservar, mas sob a ótica capitalista, a fim de não extinguir as naturais fontes econômicas, materiais, ou seja, os recursos neles existentes. Logo, as determinações legais intervieram, e um discurso de conservação, e posteriormente de preservação, tornou-se presente no aparato jurídico. Houve, dessa forma, nas diretrizes uma (re)atualização enunciativa, mas que ainda evoca, em nossa memória discursiva, os desastres ambientais e a degradação do ecossistema causados pela utilização indevida de seus recursos, com isso emergem as formações discursivas científica e ambientalista articuladas no discurso pedagógico do documento oficial.

Baseando-nos nas interpretações de R1, observamos que começa a ser construída a representação de território pelo discurso oficial: nos discursos vinculados à formação discursiva capitalista, a representação de terra também se encontra consorciada a essa ideologia. O objetivo de preservar os recursos existentes nesses territórios é, por sua vez, uma maneira politicamente correta de dizer "explorar os recursos oriundos desse espaço”, a fim de obter lucro, produção, comércio por um longo tempo.

Diante do que foi discutido, observamos que essa representação, veiculada pelo documento oficial, é constituída com base no imaginário do branco e nas condições e posição ocupada pelo enunciador. Posto isso, com intuito de promover um paralelo entre as discursividades das Diretrizes e do povo Kinikinau, expomos outro recorte que delineia a representação de território para o povo.

Todas as práticas regidas pela globalização (tras)(de)formaram, no decorrer no tempo, a relação homem/natureza, além de terem-se consolidado de maneira conflituosa, envolvendo sempre relações de poder, já que operam nos espaços da dicotomia inclusão/exclusão. Entre essas práticas elencamos o consumismo, o latifúndio, o desmatamento que 
condicionam os deslocamentos da representação de território, em especial para o índio.

$\mathrm{Na}$ atualidade, essas práticas são resultantes dos jogos de poder entretecidos por sujeitos que não estão nas bordas sociais envolvidos pelo discurso de progresso ou evolução, e, com isso, criam uma cisão em determinadas representações, já que as representações que os sujeitos criam estão relacionadas a seus processos de identificação. Dessa forma, salientamos que as representações construídas pelo branco são, em determinados aspectos, ininteligíveis para os índios. Vejamos o excerto R2:

R2: SP1: [...] a terra pra nóis... num tem que/ não tem como explica né? ele é tudo... ele:: é como se fosse uma mãe... e a mãe... a gente não se vende/ não vende... a mãe a gente cuida... então para o indígena é assim né? a terra a gente tem que cuidá... e sobrevivê da terra... porque:: como a mãe da gente... ah:: eh:: a mãe nos sustenta... então quem nos sustenta é a terra... tudo que vem da terra... são tudo o que éprodu₹ido da terra... são alimentação... água... eh.: tudo que existe:: fazparte da vida... também dos indígena... pra mim a terra é isso... é a vida.

No início de seu dizer, é frisada a separação de sua identidade em relação à identidade do branco, estabelecendo distinções marcadas por oposição, sendo as identidades construídas por marcas de classificação. (WOODWARD, 2013). A presença do referente "nóis", funcionando como uma remissão endofórica e exofórica, já que não se refere apenas ao povo que reside na comunidade, mas a todo o povo que desde a saída do Chaco Paraguaio luta pela sobrevivência do grupo, restringe a representação de terra a ser descrita apenas aos Kinikinau. Ele mostra essa oposição usando a locução "pra nóis", os Kinikinau, indicando a presença do outro silenciada no recorte, mas passível de recuperação por meio da referenciação. Outros itens lexicais como "a gente" e "nos" tonificam a distinção feita pelo sujeito entre o índio e o outro (o branco).

Uma das primeiras regularidades nesse recorte é o uso do termo "mãe" para descrever a representação de território para a comunidade. A acepção dicionarizada de "mãe" designa, conotativamente, "pessoa extremamente cuidadosa, zelosa” (BECHARA, 2011, p. 799), e é esse o sentido empregado pelo sujeito no momento em que metaforiza a representação do território: "é como se fosse uma mãe... e a mãe... a mãe a gente cuida..." Outro aspecto pertinente no trecho em que SP2 faz essa relação território/terra-mãe é a relação interdiscursiva estabelecida por meio da expressão "e a mãe... a gente não se vende/ não vende..." Ao dizer que a terra não pode ser vendida manifesta- 
se, via interdiscurso, o dizer do outro, emerge "a presença estrangeira de palavras marcadas como pertencendo a um outro discurso" (AUTHIERREVUZ, 1998, p. 193), do branco que vende, que comercializa a terra como um produto, e diante dessa perspectiva vender a terra, para o indígena, é vender a si próprio, como o deslizamento provocado pelo inconsciente nos mostra. Compreendemos, portanto, que a relação com o território é uma relação una, além, inclusive, da relação com a própria mãe: é uma relação de fidelidade, cuidado de si mesmo, consorciada a uma formação discursiva cultural, divergente da formação discursiva capitalista que emana de itens lexicais como "vende", recorrente no discurso do branco que atravessa o seu dizer.

No imaginário indígena, a terra não pode ser vendida porque ela não é de ninguém, mas, ao mesmo tempo, é de todos. Dessa expressão "a gente cuida" emana o sentido de que, diferente do branco, os indígenas cuidam de suas terras, de seus espaços: o branco, ao contrário, vende, comercializa e se desfaz desse espaço como um produto, algo que não carrega sua história, que não faz parte de si.

As palavras não têm, portanto, sentido em si mesmas, mas têm sentidos atribuídos à elas mediante a posição que o sujeito ocupa e a partir da formação discursiva que compartilha. Pelo esquecimento n 2 (PÊCHEUX, 1988), SP1 acredita ser a fonte dos discursos que enuncia quando, na verdade, retoma discursos outros situados nos campos da ecologia, do meio ambiente, do comércio, do capitalismo, tecendo sua heterogeneidade no interdiscurso.

Compreendemos que a regularidade do termo "mãe" no discurso do índio é um forte indício de demarcar as diferenças em que estão alicerçadas as representações de território para o índio e para o branco, além de corroborar a relação tradicional e cultural com o espaço, em especial pelas formas de territorialização específicas da comunidade. Por se tratar de uma territorialização que transcende os fios de afetividade e entrelaça-se a identidade, no sentido de tornar-se Kinikinau por meio do território, os efeitos de sentidos desse termo vão estar associados $a$ cultura Kinikinau, expressão que melhor pode definir a relação da comunidade com o espaço em que vive.

A recorrente utilização do pronome "tudo", como anáfora encapsuladora, em "ele é tudo" lança um leque de significações que podem estar atreladas a ela, à medida que sua acepção dicionarizada é "a totalidade, 
o essencial" (BECHARA, 2011, p. 1114). No decorrer de sua fala, o sujeito recategoriza esse "tudo" por meio do termo "mãe", que parece estar na mesma direção argumentativa simbólica, território - tudo - mãe [nos dá a] vida. Essas reflexões são conferidas pela afirmação do sujeito de que a terra, ou o território, concede tudo, assim como a mãe concede tudo o que é necessário ao filho: ela o sustenta, o alimenta, o protege.

A representação do território como mãe-provedora-protetora atravessa todo discurso dos Kinikinau: mais que um território para construir suas casas é a representação do território como um lugar onde as identidades se fortalecem, que, conforme SP2, "é a vida". Para os indígenas tudo o que a terra produz, assim como os animais, as árvores, sobretudo o lugar onde seus antepassados estão enterrados são sagrados e por isso devem ser respeitados e preservados.

\section{Considerações finais}

À medida que conhecemos o percurso histórico dos Kinikinau, as relações estabelecidas pelo grupo com outras comunidades e com a sociedade hegemônica, encontramos rastros que nos permitem compreender a construção identitária desses sujeitos. Posto que os Kinikinau são interpelados por fenômenos como a diáspora, a ação das novas tecnologias e o (con)viver entre-línguas e entreculturas, suas identidades tornam-se cada vez mais híbridas e "deslocadas" (BAUMAN, 2005, p. 18-19), implicando, portanto, representações de si, do outro e do outro sobre si, em especial representações de território.

Ainda que se sintam fora de seu lugar de origem, os Kinikinau buscam ancorar-se em objetos, memórias e em sonhos para (re)significar o espaço onde vivem e para recriar a si mesmo como um gesto de resistência. Com base nas interpretações do recorte do documento oficial, observamos que as representações de território são construídas com base no imaginário colonizado, e que a lei, cujo domínio é virtual, (re)produz no imaginário social a representação do indígena criada nos relatos missionários: selvagens, incultos. Verificamos formas linguísticas que emanam efeitos de sentido embutidos em formações discursivas capitalistas e políticas, à medida que $\mathrm{O}$ território é concebido como produto passível de compra e venda, usado para a exploração econômica a fim de obter recursos naturais, e como produto material, desvinculado de qualquer prática que protele os objetivos políticos do Estado. 
Nos dizeres Kinikinau, delineiam-se as representações de território concebido como tudo-mãe-protetora, uma tríade que não se desvencilha no fio intradiscursivo do sujeito. Para os Kinikinau, o território ou a terra é espaço de possibilidades: possibilidades de se (re)criar identidades, de se (re) significar costumes e tradições. Espaço que carrega memórias, que permite ao indígena a essência de seu ser, a vida.

Mediante o exposto, compreendemos que do discurso oficial emanam práticas discursivas coloniais, enquanto do discurso Kinikinau emergem práticas discursivas culturais e, via interdiscurso, práticas discursivas políticas. Nesse sentido, constatamos que as representações de território são construídas a partir das condições sócio-históricas e ideológicas em que os sujeitos se encontram, por isso as representações de terra para os índios divergem das representações para o branco.

Diante das análises e problematizações, constatamos que o discurso das diretrizes e dos Kinikinau caminham para sentidos e perspectivas contrárias: o primeiro, (re)afirmando a identidade marginalizada do índio, trazendo um discurso velado de bem viver às custas de uma evolução dizimadora, e o segundo, buscando fôlego para sobrevier nas tramas dos silenciamentos articuladas pelas leis, gritando à sociedade que seu povo vive e que necessita de seu território próprio, pois deste e apenas deste emana a história Kinikinau que serve como ponto de equilíbrio.

\section{Referências}

AUGÉ, M. Sobremodernidade: do mundo tecnológico de hoje ao desafio essencial do amanhã. In: MORAES, D. (Org.). Sociedade midiatizada. Rio de Janeiro: Mauad, 2006. p. 99-117. 286p.

AUTHIER-REVUZ, J. Palavras incertas: as não-coincidências do dizer. Campinas: Editora da Unicamp, 1998. 200p.

BAUMAN, Z. Identidade: entrevista a Benedetto Vecchi. Rio de Janeiro: Zahar, 2005.110p.

BHABHA, H. K. O local da cultura. Trad. Myriam Ávila, Eliana Lourenço de Lima Reis, Glaucia Renate Gonçalves. Belo Horizonte: UFMG, 2007. 441p.

BECHARA, E. Dicionário da língua portuguesa. Rio de Janeiro: Nova Fronteira, 2011. $1357 \mathrm{p}$. 
BRASIL. Ministério da Educação. Conselho Nacional de Educação. Diretrizes Curriculares Nacionais para a Educação Escolar Indígena na Educação Básica. Diário Oficial da União, Brasília, DF, 15 jun. 2012. Seção 1, p. 18. Disponível em: <https://goo.gl/kC5ZfJ>. Acesso em: 15 jul. 2015.

CANCLINI, N. G. Culturas híbridas: estratégias para entrar e sair da modernidade. Trad. Heloísa Pezza Cintrão, Ana Regina Lessa; tradução da introdução Gênese Andrade. São Paulo: Editora da Universidade de São Paulo, 2015. 352p.

CASTELLS, M. O poder da identidade. Trad. Klauss Brandini Gerhardt. São Paulo: Paz e Terra, 2010. 401p.

CORACINI, M. J. A celebração do outro: arquivo, memória e identidade de línguas (materna e estrangeira), plurilinguismo e tradução. Campinas: Mercado das Letras, 2007.248p.

CUCHE, D. A noção de cultura nas ciências sociais. Bauru: EDUSC, 1999. 260p.

FOUCAULT, M. Arqueologia do saber. Trad. Luiz Felipe Baeta Neves. 7. ed. Rio de Janeiro: Forense Universitária, 2008. 244p.

FOUCAULT, M. A ordem do discurso. Trad. Laura Fraga de Almeida Sampaio. 19. ed. São Paulo: Loyola, 2012. 80p.

FOUCAULT, M. Método. In: FOUCAULT, M. História da sexualidade I: a vontade de saber. 18. ed. Trad. Maria Thereza da Costa Albuquerque e J. A. Guilhon Albuquerque. Rio de Janeiro: Graal, 2007. p. 102-113.

FOUCAULT, M. Microfisica do poder. Trad. Roberto Machado. Rio de Janeiro: Graal, 2004. 432p.

KLEIMAN, A. B. Agenda de pesquisa e ação em Linguística Aplicada: problematizações. In: LOPES, L. P. M. (Org.). Linguistica aplicada na modernidade recente: Festschrift para Antonieta Celani. São Paulo: Parábola, 2013.

NOLASCO, E. C. Perto do coração selbaje da crítica fronteriza. São Carlos: Pedro \& João Editores, 2013. 202p.

ORLANDI, E. P. Análise de discurso: princípios \& procedimentos. 8. ed. Campinas: Pontes, 2009.110p.

ORLANDI, E. P. Lingua e conhecimento linguístico: para uma história das ideias no Brasil. São Paulo: Cortez, 2005. 360p.

PÊCHEUX, M. Semântica e discurso: uma crítica à afirmação do óbvio. Trad. Eni Puccinelli Orlandi et al. Campinas: Editora da Unicamp, 1988. 288p.

SANTOS, D. L. Pelos percursos históricos e linguísticos, o povo Kinikinau. In: V SEMINÁRIO AMÉRICA PLATINA, 2014, Dourados. Anais... Dourados: UFGD, 2014. p. 138-153. 
SOUSA, K. Análise de discurso: para além das vertentes sociológica e formalista da linguística. In: BARONAS, R. L.; MIOTELLO, V. Análise de discurso: teorizações e métodos. São Carlos: Pedro \& João Editores, 2011. p. 103-114. 309p.

SOUZA, I. Koenukunoe emo 'u: a língua dos índios Kinikinau. 2008. 196f. Tese (Doutorado em Linguística) - Instituto de Estudos da Linguagem, Universidade Federal de Campinas, 2008. 179p.

SOUZA, R. A. Sustentabilidade e processos de reconstrução identitária entre o povo indígena Kinikinau (Koinukunoen) em Mato Grosso do Sul. 2012. 58f. Dissertação (Mestrado em Desenvolvimento Sustentável) - Universidade de Brasília, Brasília, 2012.

WOODWARD, K. Identidade e diferença: uma introdução teórica e conceitual. In: SILVA, T. T. (Org.). Identidade e diferença: a perspectiva dos estudos culturais. Petrópolis: Vozes, 2013. 295p.

ZOOPI-FONTANA, M. G. Arquivo jurídico e exterioridade. A construção do corpus discursivo e sua interpretação/ interpretação. In: GUIMARÃES, E.; PAULA, M. R. B. (Org.). Sentido e memória. Campinas: Pontes, 2005. p. 93-113. 179p. 